\title{
Inuit and Polar Bears: \\ Cultural Observations from a Hunt near Resolute Bay, N.W.T.
}

\author{
GEORGE WENZEL 1
}

\begin{abstract}
The relationship between Inuit and polar bear (Ursus maritimus Phipps) is examined. The emphasis is placed on cultural aspects of Inuit polar bear hunting. A single hunt near Resolute Bay, N.W.T., is described and comparisons are made to Inuit polar bear hunting behaviour in the Clyde River area of Baffin Island.
\end{abstract}

Key words: hunting, Inuit culture, polar bear, Resolute Bay

RÉSUMÉ. L'article explore les liens entre les Inuit et l'ours blánc (Ursus maritimus Phipps), en se penchant en particulier sur les traits culturels de la chasse inuit à l'ours blanc. Une chasse près de Resolute Bay, aux T. N.-O., est décrite et ses particularités sont comparées à celles d'une chasse semblable dans la région de la rivière Clyde sur l'île Baffin.

Mots clés: chasse, culture Inuit, ours blanc, Resolute Bay

Traduit pour le journal par Maurice Guibord.

\section{INTRODUCTION}

The past several years have seen, for the first time in Canada, serious questions raised concerning native peoples' use of the environment. In the Arctic, these questions have focused on Inuit hunting of species which have traditionally been viewed as intrinsic to Inuit subsistence and culture. Now such activities are being scrutinized by biologists, conservationists, and government agencies who feel that non-traditional economic opportunities lessen the need for unrestricted hunting of species perceived by Inuit as important sources of meat and/or money. Further, the ready availability to Inuit of modern hunting technology is seen by these observers as potentially dangerous to northern wildlife populations.

A case in point is the polar bear (Ursus maritimus Phipps), which has long been the subject of international discussion and agreement (Survival Service Commission, 1970; Lentfer, 1974). Within its various levels, the Government of Canada has expressed an understanding of the Inuit need to continue hunting (see Canada's declaration ratifying the International Agreement on Conservation of Polar Bears), but also feels that the polar bear has become chiefly an economic resource. Indeed, the relationship between Inuit and this species is one which has come to be measured by government principally in quantitative terms, usually by the yardstick of hides sold and monies received (Smith and Jonkel, 1975a,b; Smith and Stirling, 1976; Stirling et al., 1978). Inuit explain their relationship to the polar bear, and to the environment in general, from a non-empirical perspective (Brody, 1975), and this is of lesser importance to biologists measuring the worth of this species to Inuit. Often, statements such as the following are encountered: "Polar bear hunting is also reputed to still be of significant cultural importance to Inuit but we are not qualified to comment on this question." (Stirling et al., 1978:57).

This self-assessed lack of qualification on the part of biologists to comment on the polar bear as a cultural resource is not surprising, since they are rarely afforded the opportunity to observe Inuit hunts. The literature on Inuit in the social and

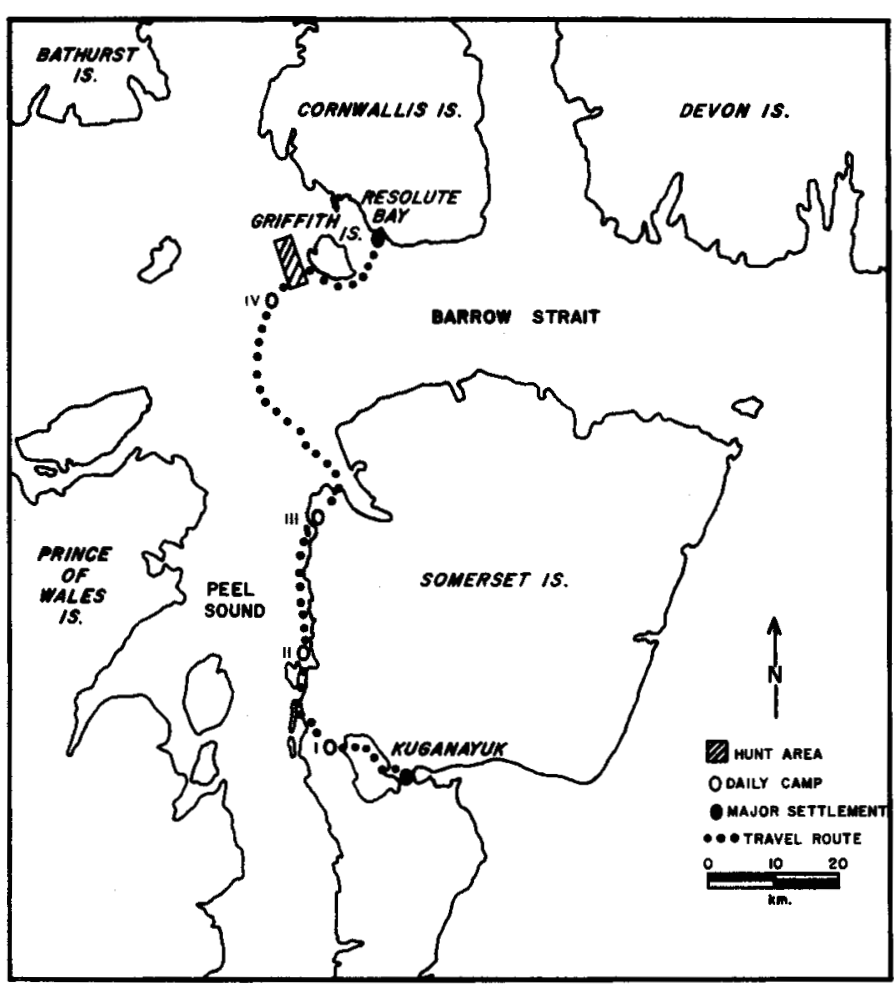

FIG. 1. Hunt route from Kuganayuk to Resolute Bay.

behavioural sciences, while enormous, shows a marked lack of observation in this area. The anthropological material on Inuit polar bear hunting has generally taken one of two directions, either extensive ethnographic description (MaryRousselière, 1957; Nelson, 1969) or exploration of the mythological place of the bear in the Inuit universe (Boas, 1888; Rasmussen, 1931; Van de Velde, 1957). Unfortunately, neither approach has contributed significantly to a clarification of the specific regard in which Inuit hold the polar bear.

It is suggested here that there are definite behavioural attributes discernible in the Inuit approach to polar bear hunting 
which may provide an indication of the cultural significance of this activity. These transcend changes in technology, economic patterns and oral tradition. The description and analysis which follow are based on data gathered while accompanying 16 Inuit travelling from the village of Kuganayuk, on Somerset Island, to Resolute Bay, the principal settlement in the High Arctic region (Fig.1). The actual hunt occurred on 14 May 1979 on the sea ice of Barrow Strait, some 40-50 km southwest of Resolute Bay. Additional data, supplementary to the field observations, were obtained from the participants in the days immediately following arrival in Resolute. The willing cooperation of the Inuit in this regard contributed greatly toward clarifying events which occurred on the hunt.

\section{BACKGROUND OF THE HUNT}

Kuganayuk is a small settlement at the western end of Creswell Bay with a permanent population of 11 Inuit (1978-79 field census), all of whom are members of a single extended family. Although sometimes described in Northwest Territories Government parlance as an "Outpost Camp", Kuganayuk has been a major residential site for Inuit since 1926 (Kemp et al., 1978), if not longer, and the oldest male resident has lived there since the mid-1920s.

The travel party was composed of all 11 Kuganayuk residents plus five kinsmen visiting from Resolute Bay; the total comprised five adult males, four adult females, and seven children. Leadership of the group fell to the oldest Kuganayuk male, following the normal isumataq (literally, the one who thinks) pattern found among Inuit (Damas, 1963, 1971). The party employed five snowmobiles and one team of 12 dogs with sledges (qamutiit) for transportation.

The group departed Kuganayuk on 10 May and broke its fourth and last camp on the evening of 14 May. The final run toward Resolute began about $1800 \mathrm{hr}$. Four of the five snowmobiles quickly outdistanced the slower dogteam, and while this lead party was crossing a low ridge of pressure ice two sets of polar bear tracks were discovered. These followed the ice ridge in a northerly direction, but off the Inuit route of travel.

It should be noted that Inuit polar bear hunting is restricted by means of a quota-and-tag system which has been in place since the late 1960s. Each Inuit community is allotted a fixed number of bears to be harvested on an annual basis; for Resolute Bay, this quota is $\mathbf{3 4}$ of which six may be taken by Kuganayuk hunters. Each individual hunter must have in his possession a polar bear tag before he kills an animal; without a tag, no polar bear hide can be sold or transported outside the limits of the N.W.T. Finally, a hunting season extending from 1 December to 31 May is enforced for all hunters.

Among Inuit there is a fear that failure to harvest all the bears allowed in a year may lead to a reduction of a community's quota the next. Therefore, hunters go to great effort as the bear season draws to a close to get the remaining animals within the legal limit. Although the Kuganayuk quota had been harvested, several tags remained from the Resolute Bay allotment. One of these was held by a young Resolute Bay hunter, who, because his snowmobile was not operating, had given it to his brother for his visit to Kuganayuk. This man had stated before our departure from Creswell Bay that he hoped to shoot a bear for his brother.

\section{DESCRIPTION OF THE HUNT}

The anatomy of any Inuit hunt, whether for polar bear or ptarmigan, may be very complicated; therefore, a schematic diagram (Fig. 2) has been included. Upon discovery of a dual set of tracks on the pressure ridge, the lead party of Inuit immediately undertook a close examination of the individual footprints (tumit) (Fig. 2, S-1). Because the hunters were aware that fresh snow had fallen near Resolute Bay some 12 hours earlier, they knew the tracks were of fairly recent origin. Two of the men undertook a detailed examination of several of the prints by testing the degree of crystallization along the edges (see Nelson, 1969:192 for a fuller description of this tracking method). From this they concluded that one trail, belonging to the smaller of the two bears, was probably no more than three to four hours old. After a brief discussion of the practicality of pursuing this animal, the entire advance group set off along the line of tracks.

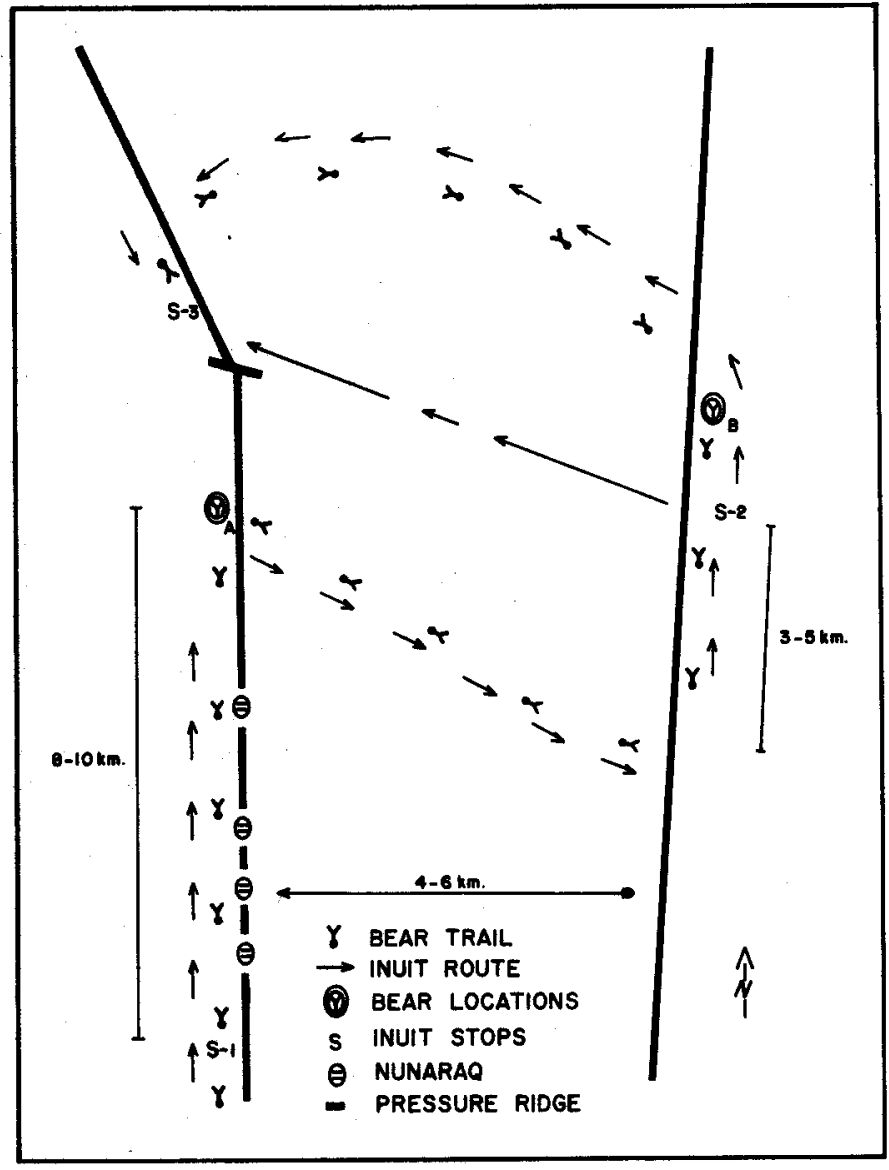

FIG. 2. Diagram of polar bear hunt described in text.

The initial pace of the party was fairly rapid as the hunters tried to catch up to the bears. Snowmobiles followed both sides of the ridge with the hunters kneeling or standing on the seats of the machines to gain a better view of the surrounding 
sea ice. Since the elder Kuganayuk Inuk (singular form of Inuit: Kingsley, 1979) was some distance behind with the dogteam, leadership of the group during this initial phase of the hunt was assumed by a Resolute Inuk in his late 30s who was acknowledged as one of Resolute Bay's best hunters.

Progress became slower as hunters stopped along the trail to examine various signs left by the bears. Two types of sites were looked at in detail: piles of excrement, which were checked for freshness; and four sites where one or both bears had broken into ringed-seal pupping dens (nunaqjat) (Fig. 2). Each time an individual completed a check, he then caught up and passed any new information to the other party members. The general consensus was that the hunters were gaining on the smaller bear.

After following the trail for roughly an hour (from $1900-2000 \mathrm{hr}$ ) and covering approximately $10 \mathrm{~km}$, the party reached a spot (Fig. $2, \otimes_{A}$ ) where the two tracks diverged, the larger track continuing in an approximately northerly direction, and the smaller bear's track leading off to the southeast. Here the Inuit again called a halt and entered into a prolonged discussion about the behaviour of the two bears. While the four men present examined both sets of footprints, both men and women took care to explain certain points to the children and one man led a three-year-old boy some distance away to one of the trails. The main focus of the discussion was which animal to follow. There seemed to be general agreement that the larger bear apparently had passed that way earlier, and was not hunting but heading directly toward the rougher ice off Cornwallis Island. The second and smaller bear was the one which had excavated the seal dens and, since its progress was slower, it appeared to be a more likely target. During this time, party members kept watch to see whether the older man was following or continuing toward Resolute Bay.

Once the group was satisfied that the dogteam was following and that there was a chance to overtake the bear that had headed toward the southeast, the advance party made rapid progress. The bear's trail led across several kilometres of smooth ice to another pressure ridge which paralleled the first. Here another brief halt was made in order to see if the rest of the party was following. Once movement was resumed, it was apparent that the Inuit expected to locate the animal shortly; no attempt was made to examine any of the several caved-in nunaqjat passed on this second trail.

After some 30-40 minutes, the hunter on the lead snowmobile called a halt (Fig. 2, S-2) and informed the group that he had sighted a polar bear amid the rough ice a short distance (1-2 km) ahead. All the adults then began an animated discussion about why the bear, which must have been alerted to our presence by the noise of the snowmobiles, did not show alarm. Each adult in turn examined the bear through binoculars and telescopic sights, and helped all the children to do so. This observation continued for approximately 30 minutes. The bear, though largely obscured by piled ice, was occasionally visible pacing a small area (Fig. 2, $\otimes_{\mathrm{B}}$ ) Despite their obvious anxiety to continue the hunt, the group chose to await the arrival of the other members of the party.

Once the rest of the Inuit arrived, the Kuganayuk isumataq immediately resumed the leadership of the hunt. It was his decision that the Resolute Bay tag-holder should proceed with the hunt using the dogteam, while two of the other hunters with snowmobiles would outdistance him and prevent the bear from escaping. One of the dogs, considered to be a particularly good hunter, was released to harass the bear. The total time spent in this last stop was approximately 70-90 minutes.

Once strategy had been discussed and each hunter knew his role, the final phase of the hunt began. The passengers who had arrived by dogteam, along with the equipment, were shifted to machine-drawn sleds and the Resolute Bay tagholder moved to the dog-sled. A brother-in-law from Kuganayuk who was experienced with sled-dogs accompanied him as driver. The team immmediately began to follow the trail of the chase dog. At the same time, two snowmobiles moved in a direct line from S-2 (Fig. 2) toward the spot where the bear had been sighted. The remaining Inuit stayed at S- 2 to see in which direction the bear began to run.

The effect on the bear of two fast-approaching snowmobiles and a chase dog was immediately evident. The bear began to run in a northeasterly direction across an expanse of flat, smooth ice. Although the bear was able to outdistance the chase dog, the snowmobiles rapidly closed the distance and began to drive the bear in a wide arc back toward the hunter and dogteam. As the machines passed the spot where the bear was first seen (Fig. 2, $\otimes_{B}$ ), one of the hunters caught a glimpse of a freshly killed immature seal near an excavated den.

As the animal crossed the flat ice, the snowmobiles closed to within approximately $100 \mathrm{~m}$ and paced the bear's right flank, causing it gradually to turn nearly $180^{\circ}$. Once the bear reached rough pressure ice, it began to slow. At this point, the pursuing Inuit were content to flank the bear, remaining slightly behind, and leave the chase dog to harass the bear. The remaining Inuit and the dogteam had meanwhile started moving on a more direct route toward the interception point (Fig. 2, S-3).

With the bear in the rough ice, it was possible to observe the dog's harassing tactics. Each time the bear faced away, the dog moved in to nip at its flanks. Several times the polar bear turned and made short lunges toward the dog, but each time the dog evaded them. Finally, the bear reached a raised ice hummock, some 2-3 $\mathrm{m}$ higher than the surrounding ice and 6-7 $\mathrm{m}$ in diameter, and made a stand against the dog. The polar bear got to its feet whenever the dog approached, but generally chose to lie down and rest. The chase from $\otimes_{B}$ to S-3 (Fig. 2) had covered roughly $10 \mathrm{~km}$ and consumed $15-20$ minutes.

The other snowmobiles reached S-3 before the dogteam. The party, including women and children, dismounted and approached the bear in an arc formation. The bear paid no apparent attention to the presence of humans, although it rose and paced the ice hummock each time the chase dog approached. The dogteam with the primary hunter arrived some 15 minutes after the rest of the group. At that time, several more dogs were released in case the bear should again begin to run, and the hunter, armed with a .243 calibre rifle, began to walk toward the bear.

The kill itself was somewhat anticlimactic after the tracking 
and chase. The hunter with the tag walked to within $10 \mathrm{~m}$ of the bear, closely followed by the group. He positioned himself quite deliberately and waited for the bear to rise and pace the ice. When the animal presented its right side, the man fired once, striking the bear in the neck and killing it. After its collapse, several of the other men moved closer and threw blocks of ice at the body to ensure that the animal was dead. Once this was confirmed, four of the Inuit attached a rope to the bear and dragged it to an area of flat ice a short distance from the hummock.

The bear, which was $2.5 \mathrm{~m}$ long and weighed approximately $230 \mathrm{~kg}$, was then butchered by the hunter and a second man. The remaining Inuit moved back and forth between the butchering area and the sleds, where the women were preparing tea. Throughout the butchering, which lasted 20-25 minutes, the oldest Kuganayuk man made suggestions to the two men working and explained to one of the male children the easiest method of dismembering a bear.

After the bear was dismembered, the old Kuganayuk isumataq directed the division of the carcass. The hunter was given the hide and the ribs, which were taken to his mother's house in Resolute Bay where his brother also resided. The other man from Resolute Bay and the two young men from Somerset Island each received a leg. The back, haunches, head and one foreleg were left at the butchering site to be used as dog food on the return journey. During the butchering, several men took time playfully to help the children examine the viscera, particularly the heart and the stomach, which was filled with seal fat.

\section{ANALYSIS AND CONCLUSIONS}

Several modes of behaviour exhibited by this Inuit hunting party require elaboration. These include the sharing of a polar bear tag between hunters, the attempts to involve the children in the hunt, and, so far unmentioned, the "psychological" approach taken by the hunters to the polar bear.

The phenomenon of tag-sharing is of interest because, while the motivation might appear to be economic, based on cash value or on the Inuit mechanism of sharing and reciprocity (Damas, 1972), data from several areas indicate that material benefit is, at best, a minor aspect of the practice. Observations of similar hunts and interviews with Inuit at Clyde River, Baffin Island (Wenzel, 1972, 1974, 1978, pers. obs.) and at Resolute Bay (Kemp et al., 1978) suggest that direct economic return to the primary hunter is rare.

At Clyde River, where I first encountered tag-sharing, the practice commonly followed was for hunters who had already shot their bear(s) to escort inexperienced or poorly equipped men on hunts and to "set up" a polar bear for them. Interviews with 10 individuals on four such hunts regarding the motivation for such actions elicited the response that the man who helped another in this fashion was assisting him to be $\mathbf{I n}$ umariit (a "real" Inuk). In discussion about possible material benefits for the men who shared their skills and gear, the point was made that if the hunters were close kin there might be some sharing of meat, but that there was no direct cash ex- change. An important fact which came out in other interviews, however, was that a man who rendered assistance was seen by others in the community as "real" Inuk himself. This prestige aspect seemed to be a primary motivating factor.

Surrogate hunting, an example of which appears in this paper and which was observed in the Resolute Bay area in 1976-77, appears to be an extension of the cooperative hunting seen on eastern Baffin Island. At Resolute Bay, however, almost all male Inuit are involved in the local wage economy (Kemp et al., 1978:174-213) and are unable in many cases to participate in polar bear hunting when a tag is available. Three cases of surrogate hunting in 1976 and one in 1977 at Resolute Bay were conducted for this reason. In interviews, participants took the position that although a man may be engaged in wage labour or hindered by lack of equipment he still has a right to a polar bear. Further, they indicated that the surrogate hunter receives a certain amount of esteem from others, both for assisting another and for successfully killing a bear.

Upon the party's arrival in Resolute Bay following the hunt described in this paper, I attempted to follow the processing of the hide and consumption of the meat brought in from the ice. Over the next several days, the members of the surrogate hunter's mother's household (four), the hunter and his family (four), and six close relatives all shared meals of polar bear at the mother's house. The other Inuit who had received parts of the bear shared their meat with their host households in Resolute Bay. The exception was the second Resolute Bay hunter, who took his meat to his father's home where he and his family often took their meals. This practice is consistent with behaviours described by Damas (1972) for other Eastern Arctic Inuit. It was more difficult to assess the final disposition of money from the sale of the hide; however, hide preparation was undertaken by the hunter's mother, and I was told that the hunter's brother (who had drawn the tag) was going to use the cash as a deposit on a new snowmobile.

The attempts to involve children closely in the hunt appear to have been related to preparing them as future hunters. The Kuganayuk isumataq had on a previous occasion explained that it was the responsibility of older people to transmit such information to the younger generation.

This hunt appears to have afforded an especially good opportunity for this, since children are rarely able to accompany men on winter hunts because of weather conditions. At each stop both men and women carefully included the children in the proceedings. As mentioned, one man took a three-year-old over to the tracks located at S-1 (Fig. 2) and touched the child's hand to the footprints to demonstrate a method of determining when the print was made. At the final halt before the chase began (S-2), both men and women helped the children use the binoculars so that they too could see the bear, and at all the stops adults made overt attempts to include children in their discussions. Such actions, although sometimes subtle, are consistent with the observations of Nelson (1969) and Briggs (1970) on the preparation of children for adult roles. In response to my later inquiries in Resolute Bay, all the adults interviewed stated that this was the Inuit method of teaching.

The last aspect of the analysis concerns a somewhat 
nebulous, yet highly relevant area; namely, the non-empirical relationship between Inuit and bears. Polar bear hunting stands out in contrast to other Inuit subsistence activities in that it is carried out with marked seriousness. In general, caribou, narwhal and seal hunts are performed in a relaxed atmosphere; however, bears are approached almost solemnly. Over a period of several years at Clyde River, I was afforded the opportunity to question local people about their feelings concerning certain animals. Clyde hunters consistently stated that the polar bear was fully as intelligent as a human being and that it understood when it was being ridiculed or belittled. On the 42 polar bear hunts I observed while in the eastern Baffin area, virtually every hunter reminded me never to joke about bears because to do so would bring future misfortune in polar bear hunting.

During the butchering of the bear at site S-3 (Fig. 2), I commented to several members of the party on the foolishness of the bear in allowing the snowmobiles to approach so closely before it began to run. Two Inuit, one in his mid-20's and the other about 35, stopped working and the older advised me that it would be best if I did not speak in such a manner. They then turned back to the bear. Two days later I visited the house in Resolute Bay where several of the Kuganayuk families were staying. While drinking tea, the camp isumataq briefly mentioned to me that he had overheard my words on the ice and that he had thought that I knew better, but that since I was a white man it probably would not have any serious effect.

It would naturally be inappropriate to stretch the data from a single hunt into any broad generalizations on the importance of the polar bear as a cultural resource for Inuit. Nevertheless, the types of behaviour observed on this hunt suggest that Inuit involvement with the white bear extends beyond the material. First and foremost, it was apparent that the adult members of the party felt that there was important information to be conveyed to their children. Second, for many hunters, there appears to be a non-material value associated with the successful pursuit of polar bears. Finally, there is an aspect of the Inuitpolar bear relationship which is a carryover from traditional times and which is still a serious consideration for many Inuit. In this regard, Nelson (1969:362) has noted a similar approach to walrus hunting among modern North Alaskan Inupiat.

\section{ACKNOWLEDGEMENTS}

Preliminary comment was offered on an earlier draft of this paper by Peter Holland and John Bradbury, both of the Department of Geography, McGill University, and Alan Cooke, McGill University Centre for Northern Studies and Research. Cartographic assistance was supplied by Thomas Millette, also of that department. My appreciation to them for their criticism and aid. I would also like to thank Martha Illaut for pointing out the correct spelling of Kuganayuk.

\section{REFERENCES}

BOAS, F. 1888. The Central Eskimo. Bureau of American Ethnology, Smithsonian Institution. Sixth Annual Report. 401-675.

BRIGGS, J. 1980. Never in Anger. Cambridge: Harvard University Press. $379 \mathrm{p}$.

BRODY, H. 1975. The Peoples Land. London: Penguin Books. 240 p.

DAMAS, D. 1963. Igluligmiut Kinship and Local Groupings: A Structural Approach. Ottawa: National Museums of Canada. Bulletin No. 196. $216 \mathrm{p}$. 1971. The problem of the Eskimo family. In: The Canadian Family. Ishwaren, K. (ed.). Toronto: Holt, Rinehart, Winston. 54-78.

1972. The central Eskimo systems of food sharing. Ethnology $\mathrm{XI}(3): 220-240$.

KEMP, W.B., WENZEL, G., JENSEN, N. and VAL, E. 1978. The Communities of Resolute and Kuvinaluk: $A$ Social and Economic Baseline Study. Toronto: Polar Gas Project. 341 p.

KINGSLEY, M.C.S. 1979. Use of the words 'Inuk' and 'Inuit'. Arctic $32(3): 281$.

LENTFER, J. 1974. Agreement on the conservation of polar bears. Polar Record 17(108):327-330.

MARY-ROUSSELIERE, G. 1957. A bear hunt on Simpson Peninsula. Eskimo 45(Sept.): 16-19.

NELSON, R.K. 1969. Hunters of the Northern Ice. Chicago: Aldine. 429 p.

RASMUSSEN, K. 1931. The Netsilik Eskimo: social life and spiritual culture. Report of the Fifth Thule Expedition, 1921-1924. Vol. VIII. Copenhagen: Glydendalske Boghandel. 542 p.

SMITH, P. and JONKEL, C. 1975a. Résumé of the trade in polar bear hides in Canada, 1972-73. Ottawa: Canadian Wildlife Service Progress Note No. 43.

1975b. Résume of the trade in polar bear hides in Canada, 1973-74. Ottawa: Canadian Wildlife Service Progress Note No. 48.

SMITH, P. and STIRLING, I. 1976. Résumé of the trade in polar bear hides in Canada, 1975-76. Ottawa: Canadian Wildlife Service Progress Note No. 66.

STIRLING, I., SCHWEINSBURG, R.E., CALVERT, W. and KILIAAN, H.P.L. 1978. Polar Bear Population Ecology-Arctic Islands Pipeline Route. Preliminary Report 1977. Environmental-Social Program Northern Pipelines. ESCOM No. AI-15. Ottawa.

SURVIVAL SERVICE COMMISSION. 1970. Polar Bears: Proceedings of the 2nd Working Meeting of Polar Bear Specialists. Supplementary Paper No. 29. Morges, Switzerland: IUCN Publication New Series. 88 p.

VAN DE VELDE, F, 1957. Nanuk, king of the arctic beasts. Eskimo 45 (Sept.):4-15. 